\title{
Changes in income-related inequalities of depression prevalence in China: a longitudinal, population study
}

\author{
Jianying Zeng ${ }^{1} \cdot$ Weiyan $\operatorname{Jian}^{1}$ (D)
}

Received: 7 January 2019 / Accepted: 8 April 2019 / Published online: 19 April 2019

(c) The Author(s) 2019

\begin{abstract}
Purpose This study aimed to measure the income-related inequality of depressive symptoms and its trends among middleaged and elderly people in China.

Methods Data were extracted from the 2011 baseline and 2015 follow-up of the China Health and Retirement Longitudinal Study (CHARLS), a nationally representative survey for people aged 45 years and more. Depressive symptoms were evaluated with the Chinese version of the ten-item Center for Epidemiologic Studies Depression Scale. Five relative income levels were derived from ratios between the participants' annual per capita household expenditure, excluding medical expenditure, and the median PCE of their cities. The concentration curve and index were used to compare the magnitude of income-related inequality between 2 years. A logistic regression model was used to control the other socio-economic factors.

Results The prevalence of depression among middle-aged and elderly people in China decreased from 37.0\% (5540 of 14,956 participants) in 2011 to $32.7 \%$ ( 5606 of 17,165 ) in 2015. However, the absolute value of the standardized concentration index increased from 0.005 to 0.028 . Although the second lowest-income group had the greatest improvement in the decline of prevalence (5.7\%, from 38.6 to $32.9 \%$ ), the lowest-income group had only the minimal decline (2.4\%, from 40.6 to $38.2 \%$ ). In 2015, there were significant differences between the lowest-income group and other four groups while the differences among other four groups were not statistically significant.

Conclusions The prevalence of depression among the middle-aged and elderly in China is declining, but the issue of incomerelated inequality has been exacerbated. The fairness of mental health deserves more attention.
\end{abstract}

Keywords Mental health equity $\cdot$ Depression $\cdot$ Concentration index $\cdot$ Relative income $\cdot$ China

\begin{tabular}{ll}
\multicolumn{2}{l}{ Abbreviations } \\
CHARLS & $\begin{array}{l}\text { China Health and Retirement Longitudinal } \\
\text { Study }\end{array}$ \\
& Per capita household expenditure \\
PCE & Years lived with disability \\
YLDs & World Health Organization \\
WHO & Communist Party of China \\
CPC & Gross domestic product \\
GDP & Center for Epidemiologic Studies Depression \\
CESD & Scale \\
CIN & Concentration index
\end{tabular}

Weiyan Jian

jianweiyan@bjmu.edu.cn

1 Department of Health Policy and Management, School of Public Health, Peking University Health Science Center, Beijing, China

\section{Introduction}

Depression is an important mental health disorder that has led to a huge global disease burden, which ranks among the top five causes of Years Lived with Disability (YLDs). In 2016, depression had caused 34.1 million YLDs [1]. According to the World Health Organization (WHO), about 300 million people worldwide suffered from depression in 2016. A meta-analysis of depression-related symptoms in Chinese elderly people from 2000 to 2010 showed that the combined prevalence of depression was $22.6 \%$ [2].

The prevalence of depression can be directly and indirectly affected by socio-economic status. People with lower-income have a higher prevalence of depression [3, 4]. Middle-aged and elderly people are more vulnerable to depression [5]. Mental health is currently facing a serious problem of inequality, and this has become an important public health problem in developing countries [6]. Previous studies indicate that the prevalence of depression varies 
greatly among different socio-economic statuses and concentrates in low-income groups [7]. There is a close relationship between income inequality and depression [8]. Similarly, China's equality-related research indicates that the depressive symptoms of Chinese elderly people tend to accumulate in lower-income groups [9]. Therefore, it is necessary to strengthen the prevention and management in vulnerable groups [10]. However, compared with the field of physical health, there is not as much research on the fairness of mental health. Moreover, the research mainly focuses on crosssectional studies. There is a lack of vertical comparison.

The study of changes in mental health equity is necessary, especially in China. In recent years, the rapid social and economic development in China has exacerbated inequality from various aspects. Therefore, the Chinese government has begun to pay attention to policy fairness. For example, in 2009, the Communist Party of China (CPC) Central Committee and the State Council released "Opinions on the Reform of the Medical and Health System" and "Key Implementation Plan for Hospital Health System Reform (2009-2011)", which put forward "Gradual Equalization of Basic Public Health Services" [11]. The goal of this policy is to perfect the equalization mechanism of basic public health services. However, we still do not know whether the interventions for the most vulnerable people were effective or whether these various measures aimed at mental health are conducive to fairness.

The purpose of this study is to describe the prevalence of depression between 2011 and 2015 and measure the income-related inequality of depressive symptoms and its trends among the middle-aged and elderly people in China.

\section{Methods}

\section{Data and sample}

This study used the 2011 CHARLS baseline and 2015 follow-up survey data. CHARLS [12], chaired by the National School of Development of Peking University, is a nationwide survey of China's population of people 45 years of age and older. This is a nationally representative survey. First, the four-stage sampling of "county (district)—village (residence)—household—individual level" was adopted. Specifically, as for the county (district) — village (neighborhood) level, CHARLS used a pro rata sampling rate based on the population scale, district and GDP (Gross domestic product). Then, 150 districts and counties were randomly selected from 30 provincial-level administrative units. Similarly, 450 villages/communities were randomly selected based on the resident population. Second, sampling for the household and individual levels was based on GPS positioning.
In this study, people aged 45 years and more and who had completed the measure of depressive symptoms were selected as participants. In data cleaning process, respondents with logic error answers or with key variables missing (i.e., response to depression scale and income-related variables) were excluded. The final sample sizes were 14,956 and 17,165 in 2011 and 2015, respectively.

\section{Variables}

\section{Dependent variables}

Depressive symptoms Depression was measured using the Chinese version of the Center for Epidemiologic Studies Depression Scale (CESD) questionnaire. Previous studies have shown that this Chinese scale has good validity and reliability [4]. The CESD scale has 10 questions, including eight negatively oriented questions (e.g., "I felt depressed") and two positively oriented questions (e.g., "I felt hopeful about the future"). Each question has four options: rarely or none of the time ( $<1$ day), some or a little of the time (1-2 days), occasionally or a moderate amount of the time (3-4 days) and most or all of the time (5-7 days), which were, respectively, counted as $0,1,2$, and 3 for negatively oriented questions and the opposite for positively oriented questions. Then, all of the scores were added to gain a total CESD score. The middle-aged and elderly people were considered to have depressive symptoms once the CESD score was 10 or over [13].

\section{Independent variables}

Relative income The income level was reflected by the annual PCE (per capita household expenditure, excluding medical expenditure). According to the empirical evidence about relative income [8], relative income in the context of mental health reflects the problem more accurately than the absolute income. Moreover, we used per capita household expenditure instead of household income because household consumption demonstrates a better distribution of living standards in low- and middle-income countries where rural and agricultural societies may cause wide income variation in the short term according to previous study [14]. Therefore, we divided the subjects' PCE by the median PCE of their cities. The ratios obtained reflected the relative income status. Then, we divided the ratios into five relative income levels.

Other variables Other variables were selected to control confounding factors that may be related to mental health problems, including age, gender, marital status, education level (illiterate, did not finish primary school, Sishu-a kind of home school, home school, elementary school, and 
middle school and above), employment, region (eastern, central and western), urban and rural areas, social activities (reflected the number of activities that the subjects attended in the last month), physical disabilities, brain damage, visual problems, and hearing problems.

\section{Statistical analysis}

This study selected concentration curves, concentration index [15] and logistic regression to analyze the issue of depression inequality. The data analysis was based on STATA software (version 13.0).

Concentration curves were chosen to reflect the issue of mental health inequality. In this study, the concentration curves represent the cumulative value of depression prevalence from the poorest to the richest, where the horizontal axis is relative income (from the poorest to the richest) and the vertical axis is the cumulative prevalence of depression. If each income group had the same prevalence, the concentration curve would be an oblique straight line, which is called the reference line. When the prevalence of depression varies among the different income groups, the concentration curve deviates from that line. If the curve is above the reference line, the depressive symptoms are concentrated in the poorer group; otherwise, it is the opposite. Also, the larger the area between the curve and the reference line, the larger the income-related inequality is.

The concentration index is defined as two times the area between the concentration curve and the reference line. A negative value represents the aggregation to the poorer population, while a positive value is the opposite. The expression of the concentration index is as follows:

$C=\frac{2}{\mu} \operatorname{cov}(h, r)$,

where $h$ represents mental health indicators (depression), $\mu$ is its mean, and $r=i / N$ represents the fractional rank of the individual $(i)$ in different income groups, where $i=1$ represents the poorest group and $i=N$ represents the richest group.

To control for the effect of other confounding variables on the concentration index, the concentration index can be standardized by regression with the following expression:

$2 \sigma_{r}^{2}\left(\frac{h_{i}}{\mu}\right)=\alpha+\beta r_{i}+\sum_{j} \delta_{j} x_{j i}+v_{i}$

where $\sigma_{r}^{2}$ is the variance of $\mathrm{r}$ and $x_{j}$ are the confounding variables that need to be controlled. The OLS estimator for $\hat{\beta}$ is the estimate of the standardized concentration index.
Besides, the logistic regression model was used to analyze the association between depression and relative incomes while controlling for the other variables listed above.

\section{Results}

Table 1 shows the characteristics of the study population in 2011 and 2015 and the prevalence of depression in various characteristic groups. In this study, the total number of respondents was 14,956 in 2011 and 17,165 in 2015, with respective average ages of 59.4 years and 60.3 years. Additionally, $48 \%$ and $49 \%$ of respondents were men, respectively. Overall, about $60 \%$ of respondents were living in an urban area, and about $68 \%$ were working at the time. The overall prevalence of depression among elderly people 45 years of age and older in China was $37.0 \%$ in 2011 and $32.7 \%$ in 2015 .

From the cross-sectional view, the prevalence of depression varied largely among different groups. To be specific, the older people had a higher prevalence of depression, except the oldest group in 2015. There was an "inflection point" in which the prevalence of the oldest people aged 75 years of age and over was $33.8 \%$, which is lower than that of 66-75-year-old group (37.4\%). There was the same distribution of prevalence both in 2011 and 2015. Females with lower education level in other marital statuses (including separated, divorced, widowed, and single) without working had a higher prevalence of depressive symptoms. Moreover, there was an uneven distribution among eastern (25.1\%), central (33.9\%) and western China (39.4\%). The urban-rural gap was large. In addition, people with four types of physical health problems had a relatively high prevalence.

From the time trend, the prevalence of depression in all types of groups showed a decline. First, the middle-aged and elderly, especially those who were 75 years of age or over, had the largest decline, which reached $12 \%$ points, and ranked first compared to the other categories. Second, there were large improvements for people with physical health problems. The prevalence of brain damage, vision problems and hearing problems decreased by $8.6,6.6$ and $7.5 \%$ points, respectively. Next, the prevalence in men dropped more than that in women (4.8 and 3.6\% points, respectively). Except for income and education categories, vulnerable groups had greater improvement, such as people with other marital statuses (including separated, divorced, widowed, and single, $6.2 \%$ points), non-working people (5.2\% points) and people in central China (5.4\% points) and in rural areas (5.1\% points), whose decline was higher than that of the average level ( $4.3 \%$ points). However, the decline in prevalence in the lowest-income level group was not the greatest one, but actually the smallest. 
Table 1 Variables description and depression prevalence comparison (2011 and 2015)

\begin{tabular}{|c|c|c|c|c|c|c|c|}
\hline & \multicolumn{3}{|c|}{ CHARLS 2011} & \multicolumn{4}{|c|}{ CHARLS 2015} \\
\hline & $N$ & $\%$ & $\begin{array}{l}\text { Depression } \\
\text { (prevalence \%) }\end{array}$ & $N$ & $\%$ & $\begin{array}{l}\text { Depression } \\
\text { (prevalence \%) }\end{array}$ & $\triangle$ Change \\
\hline \multicolumn{8}{|l|}{ Age } \\
\hline$\geq 45-55$ & 5819 & 38.9 & 31.9 & 6609 & 39.0 & 29.1 & -2.8 \\
\hline $56-65$ & 5482 & 36.7 & 39.1 & 5830 & 34.4 & 33.4 & -5.7 \\
\hline $66-75$ & 2657 & 17.8 & 40.6 & 3422 & 20.2 & 37.4 & -3.2 \\
\hline$>75$ & 994 & 6.6 & 46.0 & 1105 & 6.5 & 33.8 & -12.2 \\
\hline \multicolumn{8}{|l|}{ Gender } \\
\hline Female & 7771 & 52.0 & 43.3 & 8694 & 50.7 & 39.7 & -3.6 \\
\hline Male & 7180 & 48.0 & 30.3 & 8471 & 49.4 & 25.5 & -4.8 \\
\hline \multicolumn{8}{|l|}{ Marital status } \\
\hline Married & 13,084 & 87.5 & 35.0 & 15,106 & 88.0 & 31.0 & -4.0 \\
\hline Separated/divorced/widowed/single & 1870 & 12.5 & 51.3 & 2058 & 12.0 & 45.1 & -6.2 \\
\hline \multicolumn{8}{|l|}{ Household expenses (arranged relatively) } \\
\hline Lowest $0-20 \%$ & 2934 & 19.8 & 40.6 & 3414 & 20.0 & 38.1 & -2.5 \\
\hline $20-40 \%$ & 2993 & 20.2 & 38.6 & 3412 & 20.0 & 32.9 & -5.7 \\
\hline $40-60 \%$ & 2972 & 20.0 & 36.7 & 3445 & 20.2 & 31.9 & -4.8 \\
\hline $60-80 \%$ & 2940 & 19.8 & 35.6 & 3423 & 20.1 & 30.5 & -5.1 \\
\hline Highest $80-100 \%$ & 2986 & 20.1 & 34.2 & 3354 & 19.7 & 29.9 & -4.3 \\
\hline \multicolumn{8}{|l|}{ Education } \\
\hline Illiterate & 3959 & 26.5 & 48.3 & 3577 & 22.9 & 44.6 & -3.7 \\
\hline Did not finish primary school & 2594 & 17.4 & 44.7 & 2911 & 18.6 & 40.1 & -4.6 \\
\hline Sishu/home school/elementary school & 3330 & 22.3 & 36.6 & 3613 & 23.1 & 32.9 & -3.7 \\
\hline Middle school and above & 5066 & 33.9 & 24.6 & 5524 & 35.4 & 22.8 & -1.8 \\
\hline \multicolumn{8}{|l|}{ Working status } \\
\hline No & 4866 & 32.6 & 39.9 & 5384 & 31.4 & 34.7 & -5.2 \\
\hline Yes & 10,059 & 67.4 & 35.7 & 11,751 & 68.6 & 31.7 & -4.0 \\
\hline \multicolumn{8}{|l|}{ Residential location } \\
\hline Eastern China & 5200 & 34.8 & 29.0 & 5964 & 34.7 & 25.1 & -3.9 \\
\hline Central China & 4916 & 32.9 & 39.3 & 5557 & 32.4 & 33.9 & -5.4 \\
\hline Western China & 4840 & 32.4 & 43.4 & 5644 & 32.9 & 39.4 & -4.0 \\
\hline \multicolumn{8}{|l|}{ Residential area } \\
\hline Rural & 8893 & 59.5 & 42.2 & 10,319 & 60.1 & 37.1 & -5.1 \\
\hline Urban & 6063 & 40.5 & 29.4 & 6846 & 39.9 & 26.0 & -3.4 \\
\hline \multicolumn{8}{|l|}{ Social activity } \\
\hline Mean (SD) & $0.7(0.86)$ & - & - & 0.9 (1.09) & - & - & \\
\hline \multicolumn{8}{|l|}{ Physical disabilities } \\
\hline No & 14,363 & 96.0 & 36.3 & 15,849 & 92.3 & 31.3 & -5.0 \\
\hline Yes & 593 & 4.0 & 54.5 & 1316 & 7.7 & 49.3 & -5.2 \\
\hline \multicolumn{8}{|l|}{ Brain damage } \\
\hline No & 14,602 & 97.6 & 36.4 & 16,147 & 94.1 & 31.3 & -5.1 \\
\hline Yes & 354 & 2.4 & 62.7 & 1018 & 5.9 & 54.1 & -8.6 \\
\hline \multicolumn{8}{|l|}{ Vision problems } \\
\hline No & 14,028 & 93.8 & 35.7 & 15,245 & 88.8 & 30.3 & -5.4 \\
\hline Yes & 928 & 6.2 & 57.7 & 1920 & 11.2 & 51.1 & -6.6 \\
\hline \multicolumn{8}{|l|}{ Hearing problems } \\
\hline No & 13,747 & 91.9 & 35.6 & 14,555 & 84.8 & 30.3 & -5.3 \\
\hline Yes & 1209 & 8.1 & 53.3 & 2610 & 15.2 & 45.8 & -7.5 \\
\hline \multicolumn{8}{|l|}{ Depression } \\
\hline CES-D $<10$ & 9416 & 63.0 & - & 11,559 & 67.3 & - & - \\
\hline
\end{tabular}


Table 1 (continued)

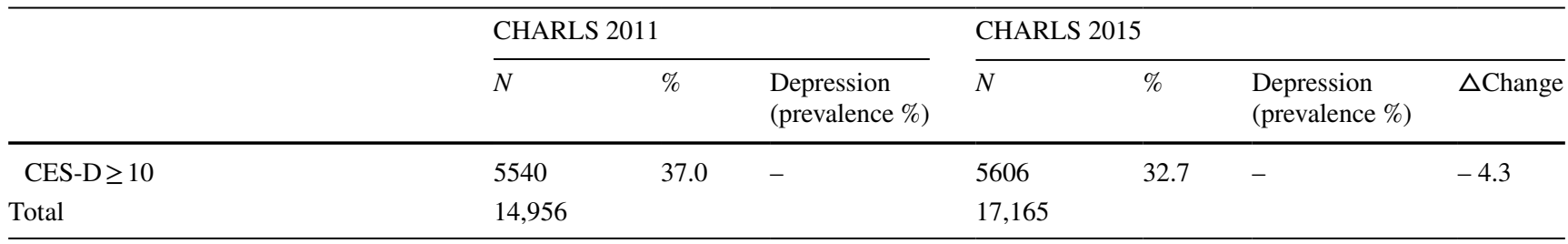

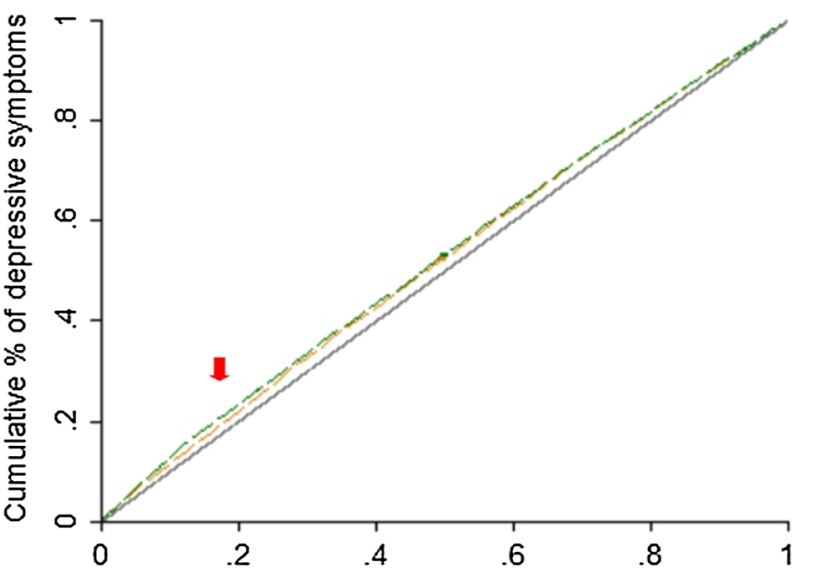

Cumulative $\%$ of people, ranked from poorest to richest

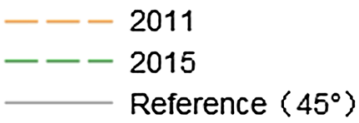

Fig. 1 Concentration curve of depression among the middle-aged and elderly in China (2011 and 2015)

Figure 1 shows the concentration curves of depression in 2011 and 2015, with relative income as the horizontal axis and the cumulative prevalence of depression as the vertical axis. Overall, the concentration curves suggest that there was income-related inequality in depressive symptoms in China. The concentration curves of the 2 years deviated upward from the reference line $\left(45^{\circ}\right)$, indicating that depressive symptoms were more prevalent in poorer people.

Then, judging by the comparison of the 2 years, the issue of inequality in 2015 was even more prominent. In 2015, the upward deviation from the reference line was greater than that in 2011. The upward deviation mainly concentrated in the lower-income groups (indicated by the red arrow), suggesting that inequality tends to be aggravated in lower-income groups.

To explore the distribution of inequality, five relative income levels were created. Table 2 shows the stratification of the five relative income levels in the 2 years. The gap between the richest and poorest was increasing. In 2011, the median of the highest income group was 6 times higher than that of the lowest-income group, but by 2015, the ratio had reached 8 .

Table 3 reflects the prevalence of depression and its changes in different income levels in the 2 years. Table 3 also compares the inequality differences between the 2 years using concentration indexes. First, the prevalence of depression between the 2 years declined in all income levels, and the differences were statistically significant. However, in the lowest-income group, the decline (2.47\%) was much lower than that of the other four groups, and the prevalence of depression in the lowest-income group in 2015 was prominently higher than in the other four groups. Moreover, the absolute value of the concentration index in 2015 was $0.05(P<0.01$, compared to 0$)$ higher than 0.038 in 2011 ( $P<0.01$, compared to 0$)$, but difference for concentration index between 2011 and 2015 was not statistically significant $(P=0.19)$. However, after controlling for other confounding factors, the standardized concentration index increased from 0.005 in $2011(P=0.38$, compared to 0$)$ to 0.028 in $2015(P<0.01$, compared to 0$)$, and this difference was statistically significant $(P<0.01)$, which proves that the issue of depression equity was more prominent in 2015. (For details on the standardization of the concentration index, see Table 6 in Appendix).

Table 4 shows the logistic regression of depression with the different income levels where the lowest-income group is
Table 2 Income level (PCE) in years 2011 and 2015

\begin{tabular}{lccccccc}
\hline Income level (PCE) & 2011 & & & & & & \\
\cline { 7 - 8 } & Median & Lower quartile & Upper quartile & & Median & Lower quartile & Upper quartile \\
\hline The poorest & 6263 & 3740 & 9990 & & 7640 & 4695 & 11,840 \\
Lower 20\% & 11,956 & 8011 & 18,240 & & 15,634 & 11,220 & 21,860 \\
Medium 20\% & 17,198 & 11,020 & 24,784 & & 22,495 & 16,820 & 30,378 \\
Higher 20\% & 22,865 & 15,784 & 32,743 & & 31,840 & 23,640 & 43,360 \\
The richest & 37,880 & 24,340 & 59,704 & & 63,435 & 42,160 & 104,379 \\
Total & 16,880 & 9129 & 28,660 & & 22,607 & 12,655 & 39,640 \\
\hline
\end{tabular}

$P C E$ per capita expenditure

$\mathrm{PCE}$ is calculated in $\mathrm{CNY}$ 
Table 3 Prevalence of depression in different income (measured by PCE) groups

\begin{tabular}{lllllllll}
\hline Year & \multicolumn{2}{l}{ Prevalence of depression by PCE quintile } & & Average depression & Concentration index & Standardized CIN $\Delta$ \\
\cline { 2 - 6 } & Poorest & 2nd & Middle & 4th & Richest & & \\
\hline 2011 & $40.62 \%$ & $38.59 \%$ & $36.71 \%$ & $35.58 \%$ & $34.17 \%$ & $37.0 \%$ & $-0.038^{* * *}$ & $-0.005^{\#}$ \\
2015 & $38.15 \%$ & $32.87 \%$ & $31.90 \%$ & $30.55 \%$ & $29.89 \%$ & $32.7 \%$ & $-0.050^{* * *}$ & $-0.028 * * *$ \\
Change & $-2.47 \%$ & $-5.72 \%$ & $-4.81 \%$ & $-5.03 \%$ & $-4.28 \%$ & $-4.3 \%$ & -0.012 & -0.023 \\
$X^{2}$ & 4.0 & 22.6 & 16.4 & 18.3 & 13.5 & 67.7 & \\
$P$ & 0.045 & $<0.001$ & $<0.001$ & $<0.001$ & $<0.001$ & $<0.001$ & \\
\hline
\end{tabular}

$\Delta$ controlling for age, gender, marital status, occupation, education, location and region (Table 6 in appendix)

$P C E$ per capita expenditure

${ }^{\#}$ Means $P=0.38, * * *$ means $P<0.01$

the reference group. Based on this logistic regression, being a woman, in other marital statuses (including separated, divorced, widowed, and single), with lower education level, less social activities, physical disabilities, brain damage and vision problems, without working, and living in rural area demonstrate a higher risk of depressive symptoms.

Table 5 shows the test for differences in regression coefficients of different income levels. In 2011, differences in the prevalence of depression among the different income groups were not statistically significant. However, in 2015, the other four groups demonstrated a significantly lower prevalence of depression compared to the lowest-income group. Using the lowest-income group as a reference, the odds ratios of depression for the lower-income, middle-income, higher income, and highest income were $0.875(P<0.05), 0.898$ $(P<0.01)$, and $0.843(P<0.01)$ and $0.872(P<0.01)$, respectively. These differences mainly existed in the comparison between the lowest-income group and the other groups. In other words, the differences between the other four groups were not statistically significant, except for the coefficient of the middle-income group compared to the higher income group $\left(X^{2}=1.18, P<0.05\right)$. This finding proves that the inequality was highlighted in 2015 and that the lowest-income group was the main reason for the inequality.

\section{Discussion}

Overall, this study found that the prevalence of depression among people 45 years of age and over in China is declining, especially for some vulnerable groups such as the elderly and people with disabilities. This finding suggests that China has made active efforts to improve mental health. From 2000 to 2015 , four health policies in China played a major role in the field of mental health [16]. These policies are "China's Mental Health Plan 2002-2010" (hereinafter referred to as the "Plan") in 2002, the State Council General Office's 2004 Guidelines on Further Strengthening Mental Health Work, the 2008 National Mental Health Work (2008-2015) (hereinafter referred to as the "Outline") and the first mental health law "Mental Health Law of the People's Republic of China" that was put into force in 2013. Specifically, the "Plan" and the "Outline" pointed out that interventions should be strengthened in the vulnerable groups, including the elderly, women, children and the disabled. This study proves that some of the key population psychological behavior interventions have achieved some success.

However, the issue of income-related inequality has been exacerbated. The lowest-income group is the main contributor of this income-related inequality. Research on income inequality and depression corroborates this point, mentioning that the most serious inequality occurs in the lowest-income group, with no significant difference between the secondary and above income levels [17]. Policy analysis pointed out that although China has implemented the policies of equalization of public health services since 2009 , mental health problems are not specified in the above equalization policies. Besides, existing mental health policies mainly focus on the management and treatment of severe mental illnesses, and there are no specific instructions in the mental health policies for the poor. Moreover, some policy studies have pointed out that the implementation of mental health policies is alterable in practice, especially in poorer areas. The problem of unbalanced mental health resources in poorer areas is more prominent. In central and western China, the number of psychiatric beds in certain municipalities and county-wide administrative areas is zero [18]. The existence of such a "blank space" of mental health service made the financial aid for the poorest people invalid because they had no chance to access to these basic mental health services.

Another reason for the insignificant improvement in the lowest-income group is the increase in income inequality. Although the economic level of each group has risen, the gap between the richest and the poorest has increased significantly. The theory about relative income points out the negative relationship between inequality and health [19] and states that income inequality aggravates the prevalence of depression. It also points out that income inequality affects health mainly 
Table 4 Odds ratios for logistic regression of depression with socio-economic status and physical health variables

\begin{tabular}{|c|c|c|c|c|}
\hline & \multicolumn{2}{|l|}{ CHARLS 2011} & \multicolumn{2}{|l|}{ CHARLS 2015} \\
\hline & Odds ratio & SE & Odds ratio & SE \\
\hline \multicolumn{5}{|l|}{ PCE (arrange relatively) } \\
\hline Lowest $0-20 \%$ & 1.0 (Reference) & & 1.0 (Reference) & \\
\hline $20-40 \%$ & 1.020 & $(0.0575)$ & $0.875^{* *}$ & $(0.0488)$ \\
\hline $40-60 \%$ & 0.988 & $(0.0561)$ & $0.898^{*}$ & $(0.0504)$ \\
\hline $60-80 \%$ & 1.047 & $(0.0602)$ & $0.843 * * *$ & $(0.0483)$ \\
\hline Highest $80-100 \%$ & 1.024 & $(0.0596)$ & $0.872 * *$ & $(0.0510)$ \\
\hline \multicolumn{5}{|l|}{ Age } \\
\hline$\geq 45-55$ & 1.0 (Reference) & & 1.0 (Reference) & \\
\hline $56-65$ & $1.093 * *$ & $(0.0479)$ & 0.983 & $(0.0444)$ \\
\hline $66-75$ & 1.012 & $(0.0577)$ & 0.979 & $(0.0534)$ \\
\hline$>75$ & 0.993 & $(0.0855)$ & $0.672 * * *$ & $(0.0588)$ \\
\hline \multicolumn{5}{|l|}{ Gender } \\
\hline Female & 1.0 (Reference) & & 1.0 (Reference) & \\
\hline Male & $0.621 * * *$ & $(0.0246)$ & $0.542 * * *$ & $(0.0216)$ \\
\hline \multicolumn{5}{|l|}{ Marital status } \\
\hline Married & 1.0 (Reference) & & 1.0 (Reference) & \\
\hline Separated/divorced/widowed/single & $1.539 * * *$ & $(0.0856)$ & $1.502 * * *$ & $(0.0839)$ \\
\hline \multicolumn{5}{|l|}{ Education } \\
\hline Illiterate & 1.0 (Reference) & & 1.0 (Reference) & \\
\hline Did not finish primary school & 1.087 & $(0.0594)$ & 0.987 & $(0.0542)$ \\
\hline Sishu/home school/Elementary school & $0.855^{* * *}$ & $(0.0453)$ & $0.841 * * *$ & $(0.0459)$ \\
\hline Middle school and above & $0.568 * * *$ & $(0.0311)$ & $0.610 * * *$ & $(0.0341)$ \\
\hline \multicolumn{5}{|l|}{ Working status } \\
\hline No & 1.0 (Reference) & & 1.0 (Reference) & \\
\hline Yes & $0.842 * * *$ & $(0.0372)$ & 0.942 & $(0.0408)$ \\
\hline \multicolumn{5}{|l|}{ Residential location } \\
\hline Eastern China & 1.0 (Reference) & & 1.0 (Reference) & \\
\hline Central China & $1.618^{* * *}$ & $(0.0718)$ & $1.506 * * *$ & $(0.0683)$ \\
\hline Western China & $1.717 * * *$ & $(0.0763)$ & $1.713 * * *$ & $(0.0769)$ \\
\hline \multicolumn{5}{|l|}{ Residential areas } \\
\hline Rural & 1.0 (Reference) & & 1.0 (Reference) & \\
\hline Urban & $0.638 * * *$ & $(0.0258)$ & $0.684 * * *$ & $(0.0277)$ \\
\hline \multicolumn{5}{|l|}{ Social activity } \\
\hline Mean (SD) & $0.841 * * *$ & $(0.0188)$ & $0.906 * * *$ & $(0.0166)$ \\
\hline \multicolumn{5}{|l|}{ Physical disabilities } \\
\hline No & 1.0 (Reference) & & 1.0 (Reference) & \\
\hline Yes & $1.815^{* * *}$ & $(0.166)$ & $1.743 * * *$ & $(0.114)$ \\
\hline \multicolumn{5}{|l|}{ Brain damage } \\
\hline No & 1.0 (Reference) & & 1.0 (Reference) & \\
\hline Yes & $2.468 * * *$ & $(0.297)$ & $1.945^{* * *}$ & $(0.141)$ \\
\hline \multicolumn{5}{|l|}{ Vision problems } \\
\hline No & 1.0 (Reference) & & 1.0 (Reference) & \\
\hline Yes & $1.641 * * *$ & $(0.123)$ & $1.560 * * *$ & $(0.0867)$ \\
\hline \multicolumn{5}{|l|}{ Hearing problems } \\
\hline No & 1.0 (Reference) & & 1.0 (Reference) & \\
\hline Yes & $1.464 * * *$ & $(0.0976)$ & $1.414 * * *$ & $(0.0704)$ \\
\hline
\end{tabular}

*Means $P<0.1$, **means $P<0.05$, ***means $P<0.01$ 
Table 5 Test for differences in regression coefficients by different income levels

\begin{tabular}{|c|c|c|c|c|c|c|c|c|}
\hline \multirow{2}{*}{$\begin{array}{l}\text { Chi squared } \\
\text { test }\end{array}$} & \multicolumn{4}{|c|}{ Model in 2011} & \multicolumn{4}{|c|}{ Model in 2015} \\
\hline & $\overline{\beta_{1}}$ & $\beta_{2}$ & $\beta_{3}$ & $\beta_{4}$ & $\beta_{1}$ & $\beta_{2}$ & $\beta_{3}$ & $\beta_{4}$ \\
\hline \multicolumn{9}{|l|}{$\beta_{1}$} \\
\hline$\beta_{2}$ & 0.12 & & & & $5.75^{* *}$ & & & \\
\hline$\beta_{3}$ & 0.04 & 0.31 & & & $3.67 *$ & 0.22 & & \\
\hline$\beta_{4}$ & 0.65 & 0.22 & 1.04 & & $8.83 * * *$ & 0.40 & $1.18^{* *}$ & \\
\hline$\beta_{5}$ & 0.17 & 0.01 & 0.39 & 0.15 & $5.51 * *$ & 0.00 & 0.26 & 0.30 \\
\hline
\end{tabular}

$\beta 1, \beta 2, \beta 3, \beta 4$, and $\beta 5$ correspond to the regression coefficients for the lowest-income group to the highest income group

*Means $P<0.1$, **means $P<0.05$, ***means $P<0.01$ at the psychological level [20]. A meta-analysis of income inequality and mental health states that income inequality does have a negative impact on mental health [21]. In summary, persistent income inequality increases the prevalence of depression among people at lower socio-economic levels.

This study was based on self-reported data on depressive symptoms over a period of 1 week. More objective measurement of depression and its equality issue are needed. And the gap between the lowest-income group and the second lowest-income group deserves more attention. In 2016, China launched the "Thirteenth Five-year" plan to shake off poverty and "ensure that the poor in rural areas under the current standards in China achieve the goal of eradicating poverty". The coordinated development of national income and national health requires income-related equality of mental health. In January 2017, China's National Health and Family Planning Commission (NHFPC) released "Guiding Opinions on Strengthening Mental Health Services", which sets a goal of achieving "universal mental health literacy" in 2030. Many attempts have been made worldwide on the issue of inequality in mental health. The best-known of these is the proposal of Mental Health Gap Action Programme (mhGAP) from WHO. The mhGAP targets poorer areas and aims to reduce the impact of the gap between the rich and poor on mental health. It has introduced a set of guidelines for mental illness interventions (mhGAP-IG) in low- and middle-income areas since 2010 [22] and launched the second application of the mhGAP Intervention Guide in 2017, which can help "non-professional" public health service providers to diagnose and treat mental health conditions. At present, mhGAP has conducted several projects in China that are related to behavioral disorders among children and adolescents, but interventions aimed at the wider Chinese population are still under investigation.

\section{Conclusions}

The prevalence of depression among people 45 years of age and over in China is declining from 2011 to 2015, especially for some vulnerable groups including the elderly and people with disabilities, but the issue of income-related inequality has been exacerbated. While the second lowestincome group had the greatest improvement in the decline of prevalence, the lowest-income group had only the minimal decline. The lowest-income group is the main factor contributing to the inequality and the differences of prevalence between the other four groups were not statistically significant. Policy analysis pointed out that China's current policy on equalization of public health services has not specifically included the issue of mental health. However, under the requirement of the Healthy China strategy, the fairness of mental health deserves attention.

Acknowledgements Thank you to the National School of Development of Peking University for providing the CHARLS data used in this study.

Author contributions JZ participated in the design of the study, data analysis, data interpretation, statistical methods, and drafting of the manuscript. WJ participated in the design of study, statistical methods, drafting of the manuscript, and supervision. Both authors read and approved the final manuscript for submission.

Funding This study was funded by National Natural Science Foundation of China (Grant number 71774003).

\section{Compliance with ethical standards}

Conflict of interest The authors have no conflicts to declare.

Ethic approval and consent to participate The manuscript does not contain clinical studies or patient data. The need for ethic approval was waived because data were extracted from open database.

Availability of data and materials The datasets analyzed during the current study are available in China Health and Retirement Longitudinal Study (CHARLS), carried out by the National School of Development of Peking University. [http://charls.pku.edu.cn/en].

Open Access This article is distributed under the terms of the Creative Commons Attribution 4.0 International License (http://creativeco mmons.org/licenses/by/4.0/), which permits unrestricted use, distribution, and reproduction in any medium, provided you give appropriate credit to the original author(s) and the source, provide a link to the Creative Commons license, and indicate if changes were made. 
Table 6 The standardization of the concentration index

\begin{tabular}{lcccrr}
\hline Variables & Coefficient & $95 \%$ CI & & $t$ & $P$ \\
\hline Year 2011 & & & & & \\
PCE (arrange relatively) & $-0.005^{\mathrm{a}}$ & -0.0174 & 0.00669 & -0.870 & 0.384 \\
Age & 0.00344 & -0.00102 & 0.00790 & 1.514 & 0.130 \\
Gender & -0.0388 & -0.0462 & -0.0315 & -10.35 & $<0.001$ \\
Education & -0.0222 & -0.0255 & -0.0189 & -13.18 & $<0.001$ \\
Marriage & 0.0435 & 0.0328 & 0.0543 & 7.926 & $<0.001$ \\
Occupation & -0.0188 & -0.0271 & -0.0105 & -4.434 & $<0.001$ \\
Location & -0.0472 & -0.0546 & -0.0397 & -12.38 & $<0.001$ \\
Region & 0.0290 & 0.0248 & 0.0331 & 13.76 & $<0.001$ \\
Constant & 0.166 & 0.143 & 0.188 & 14.63 & $<0.001$ \\
Year 2015 & & & & -4.203 & $<0.001$ \\
PCE (arrange relatively) & $-0.028^{\mathrm{a}}$ & -0.0410 & -0.0149 & -0.445 & 0.657 \\
Age & -0.00106 & -0.00576 & 0.00363 & -13.78 & $<0.001$ \\
Gender & -0.0560 & -0.0640 & -0.0481 & -11.96 & $<0.001$ \\
Education & -0.0221 & -0.0257 & -0.0184 & 7.615 & $<0.001$ \\
Marriage & 0.0456 & 0.0338 & 0.0573 & -2.734 & $<0.001$ \\
Occupation & -0.0123 & -0.0211 & -0.00348 & -11.42 & $<0.001$ \\
Location & -0.0468 & -0.0548 & -0.0388 & 14.62 & $<0.001$ \\
Region & 0.0334 & 0.0289 & 0.0379 & 14.98 & $<0.001$ \\
Constant & 0.182 & 0.159 & 0.206 & & -1 \\
\hline Coefient & & & & & \\
\hline
\end{tabular}

${ }^{\mathrm{a}}$ Coefficient for PCE is the standardized CIs

\section{Appendix}

See Table 6.

\section{References}

1. Vos T, Abajobir AA, Abbafati C, Abbas KM, Abate KH et al (2017) Global, regional, and national incidence, prevalence, and years lived with disability for 328 diseases and injuries for 195 countries, 1990-2016: a systematic analysis for the Global Burden of Disease Study 2016. Lancet (London, England) 390(10100):1211-1259. https://doi.org/10.1016/s0140 -6736(17)32154-2 (Epub 2017/09/19.PMID: 28919117)

2. Nie H, Zhang X (2011) A Meta Analysis of the Prevalence of Depression in Chinese Elderly from 2000 to 2010. Chin J Gerontol 31(17):3349-3352. https://doi.org/10.3969/j. issn.1005-9202.2011.17.066

3. Veenstra G (2000) Social capital, SES and health: an individual-level analysis. Soci Sci Med 50(5):619-629. https://doi. org/10.1016/S0277-9536(99)00307-X (PMID)

4. Lei X, Sun X, Strauss J, Zhang P, Zhao Y (2014) Depressive symptoms and SES among the mid-aged and elderly in China: evidence from the China Health and Retirement Longitudinal Study national baseline. Social Sci Med (1982) 120:224-232. https://doi. org/10.1016/j.socscimed.2014.09.028 (Epub 2014/09/28.PMID: 25261616)

5. Who.int [Internet] (2017) Mental health of older adults; http:// www.who.int/mediacentre/factsheets/fs381/en/. Accessed 27 Dec 2017
6. Ni Y, Tein JY, Zhang M, Yang Y, Wu G (2017) Changes in depression among older adults in China: a latent transition analysis. $\mathrm{J}$ Affect Disord. 209:3-9. https://doi.org/10.1016/j.jad.2016.11.004 (Epub 2016/11/21.PMID: 27866046)

7. Han KM, Han C, Shin C, Jee HJ, An H, Yoon HK et al (2018) Social capital, socioeconomic status, and depression in community-living elderly. J Psychiatr Res. 98:133-140. https://doi. org/10.1016/j.jpsychires.2018.01.002 (Epub 2018/01/21.PMID: 29351862)

8. Bechtel L, Lordan G, Rao DS (2012) Income inequality and mental health-empirical evidence from Australia. Health Econ 21(Suppl 1):4-17. https://doi.org/10.1002/hec.2814 (Epub 2012/05/11.PMID: 22556000)

9. Xu Y, Yang J, Gao J, Zhou Z, Zhang T, Ren J et al (2016) Decomposing socioeconomic inequalities in depressive symptoms among the elderly in China. BMC Public Health 16(1):1214. https://doi. org/10.1186/s12889-016-3876-1 (Epub 2016/12/03.PMID: 27905918)

10. Weinberger AH, Gbedemah M, Martinez AM, Nash D, Galea S, Goodwin RD (2017) Trends in depression prevalence in the USA from 2005 to 2015: widening disparities in vulnerable groups. Psychol Med. https://doi.org/10.1017/s0033291717002781 (Epub 2017/10/13.PMID: 29021005)

11. Zheng J, Guan Z (2012) The status quo of research on the equalization of public health service in China. Chin J Health Policy 5(8):62-66. https://doi.org/10.3969/j.issn.1674-2982.2012.08.013

12. Zhao Y, Strauss J, Yang G et al (2013) China Health and Retirement Longitudinal Study, 2011-2012 National Baseline Users' Guide. Peking University Press, Beijing

13. Andresen EM, Malmgren JA, Carter WB, Patrick DL (1994) Screening for depression in well older adults: evaluation of a short form of the CES-D (Center for Epidemiologic Studies Depression Scale). Am J Prev Med 10(2):77-84 Epub 1994/03/01PMID: 8037935 
14. Deaton A, Zaidi S (2002) Guidelines for constructing consumption aggregates for welfare analysis [Online]. Washington, DC. http://www-wds.worldbank.org/external/default/WDSContent Server/IW3P/IB/2002/07/31/000094946_02071304010552/Rende red/PDF/multi0page.pdf. Accessed 1 Mar 2019

15. O'Donnell O, Van Doorslaer E, Wagstaf A, Lindelow M (2007) Analyzing health equity using household survey data: a guide to techniques and their implementation. The World Bank, Herndon

16. Ma H, Liu J, Yu X (2009) Important mental health policy documents and speeches in recent years in China. Chin Ment Health J 23(12):840-843. https://doi.org/10.3969/j. issn.1000-6729.2009.12.002

17. Ahern J, Galea S (2006) Social context and depression after a disaster: the role of income inequality. J Epidemiol Commun Health. 60(9):766-770. https://doi.org/10.1136/jech.2006.042069 (Epub 2006/08/15.PMID: 16905720)

18. Chen Y, Wu L, Liu F (2015) The equality of spatial distribution of mental health resources under the concept of equalization of public health services. Seeker 10:24-28. https://doi.org/10.16059 /j.cnki.cn43-1008/c.2015.10.005

19. Subramanyam M, Kawachi I, Berkman L, Subramanian SV (2009) Relative deprivation in income and self-rated health in the United States. Soc Sci Med (1982) 69(3):327-334. https://doi. org/10.1016/j.socscimed.2009.06.008 (Epub 2009/06/26.PMID: 19552992)

20. Fiscella K, Franks P (2000) Individual income, income inequality, health, and mortality: what are the relationships? Health Serv Res 35(1 Pt 2):307-318 (Epub 2000/04/25PMID: 10778817)

21. Ribeiro WS, Bauer A, Andrade MCR, York-Smith M, Pan PM, Pingani L et al (2017) Income inequality and mental illnessrelated morbidity and resilience: a systematic review and metaanalysis. Lancet Psychiatry 4(7):554-562. https://doi.org/10.1016/ s2215-0366(17)30159-1 (Epub 2017/05/30.PMID: 28552501)

22. World Health Organization (2016) mhGAP intervention guide for mental, neurological and substance use disorders in non-specialized health settings. World Health Organization, Geneva 